\title{
Anti-inflammatory potential of 2-styrylchromones regarding their interference with arachidonic acid metabolic pathways
}

\author{
Ana Gomes ${ }^{a}$, Eduarda Fernandes ${ }^{a, *}$, Artur M.S. Silva ${ }^{b}$, Diana C.G.A. Pinto ${ }^{b}$, \\ Clementina M.M. Santos ${ }^{\mathrm{b}, \mathrm{c}}$, José A.S. Cavaleiro ${ }^{\mathrm{b}}$, José L.F.C. Lima ${ }^{\mathrm{a}}$ \\ ${ }^{a}$ REQUIMTE, Departamento de Química-Física, Faculdade de Farmácia, Universidade do Porto, Rua Aníbal Cunha, 164, 4099-030 Porto, Portugal \\ bepartamento de Química \& QOPNA, Universidade de Aveiro, 3810-193 Aveiro, Portugal

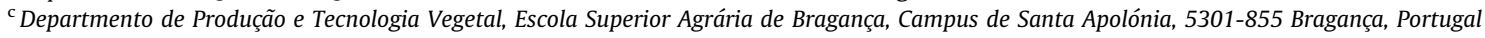

\begin{abstract}
A B S T R A C T
Cyclooxygenases (COXs) are the key enzymes in the biosynthesis of prostanoids. COX- 1 is a constitutive enzyme while the expression of COX-2 is highly stimulated in the event of inflammatory processes, leading to the production of large amounts of prostaglandins (PGs), in particular $\mathrm{PGE}_{2}$ and $\mathrm{PGI}_{2}$, which are pro-inflammatory mediators.

Lipoxygenases (LOXs) are enzymes that produce hydroxy acids and leukotrienes (LTs). 5-LOX metabolizes arachidonic acid to yield, among other products, $\mathrm{LTB}_{4}$, a potent chemoattractant mediator of inflammation.

The aim of the present work was to evaluate the anti-inflammatory potential of 2-styrylchromones (2-SC), a chemical family of oxygen heterocyclic compounds, vinylogues of flavones (2-phenylchromones), by studying their COX-1 and COX-2 inhibitory capacity as well as their effects on the $\mathrm{LTB}_{4}$ production by stimulated human polymorphonuclear leukocytes (PMNL).

Some of the tested 2-SC were able to inhibit both COX-1 activity and $\mathrm{LTB}_{4}$ production which makes them dual inhibitors of the COX and 5-LOX pathways. The most effective compounds in this study were those having structural moieties with proved antioxidant activity $\left(3^{\prime}, 4^{\prime}\right.$-catechol and $4^{\prime}$-phenol substituted B-rings).

This type of compounds may exhibit anti-inflammatory activity with a wider spectrum than that of classical non-steroidal anti-inflammatory drugs (NSAIDs) by inhibiting 5-LOX product-mediated inflammatory reactions, towards which NSAIDs are ineffective.
\end{abstract}

\section{Introduction}

Arachidonic acid is the most abundant polyunsaturated fatty acid in the phospholipid bilayer of cell membranes. This secondmessenger molecule is released by phospholipase $A_{2}$ in activated cells and further metabolized in different eicosanoids by the cyclooxygenase and lipoxygenase pathways (Fig. 1). Cyclooxygenases (COXs) are the key enzymes in the biosynthesis of prostanoids. In mammalian cells, COXs exist in at least two isoforms (COX-1 and COX-2). COX-1 is a constitutive enzyme, expressed in almost every cell type, responsible for the physiological production of prostaglandins (PGs) i.e., $\mathrm{PGI}_{2}, \mathrm{PGE}_{2}, \mathrm{PGF}_{2 \alpha}$ and $\mathrm{PGD}_{2}$, in diverse organs and thromboxane $\mathrm{A}_{2}$ in platelets. COX-

\footnotetext{
* Corresponding author. Tel.: +351 222078968; fax: +351 222078961 .

E-mail address: egracas@ff.up.pt (E. Fernandes).
}

2 , on the other hand, is usually absent in most tissues (with the exception of kidney, parts of the brain, and gravid uterus where COX-2 is constitutive) but its expression can be readily induced by numerous stimuli such as growth factors, tumor promoters, or cytokines [1,2]. The earliest expression of COX-2 is detected in stromal cells, but it also can be found in multiple cells, like epithelial, endothelial, and stromal cells in several types of tumors [3]. In addition, COX-2 is highly expressed by cells that are involved in inflammation (e.g., neutrophils, macrophages, monocytes, mast cells, synoviocytes), emerging as the isoform primarily responsible for the synthesis of the prostanoids involved in pathological processes, such as acute and chronic inflammatory states. These inflammation-related cell types can be stimulated by lipopolysaccharide, phorbol esters, cytokines, or growth factors, producing large amounts of PGs, in particular $\mathrm{PGE}_{2}$ and $\mathrm{PGI}_{2}$, which are proinflammatory mediators that increase vascular permeability and promote edema at the sites of inflammation. Furthermore, these 


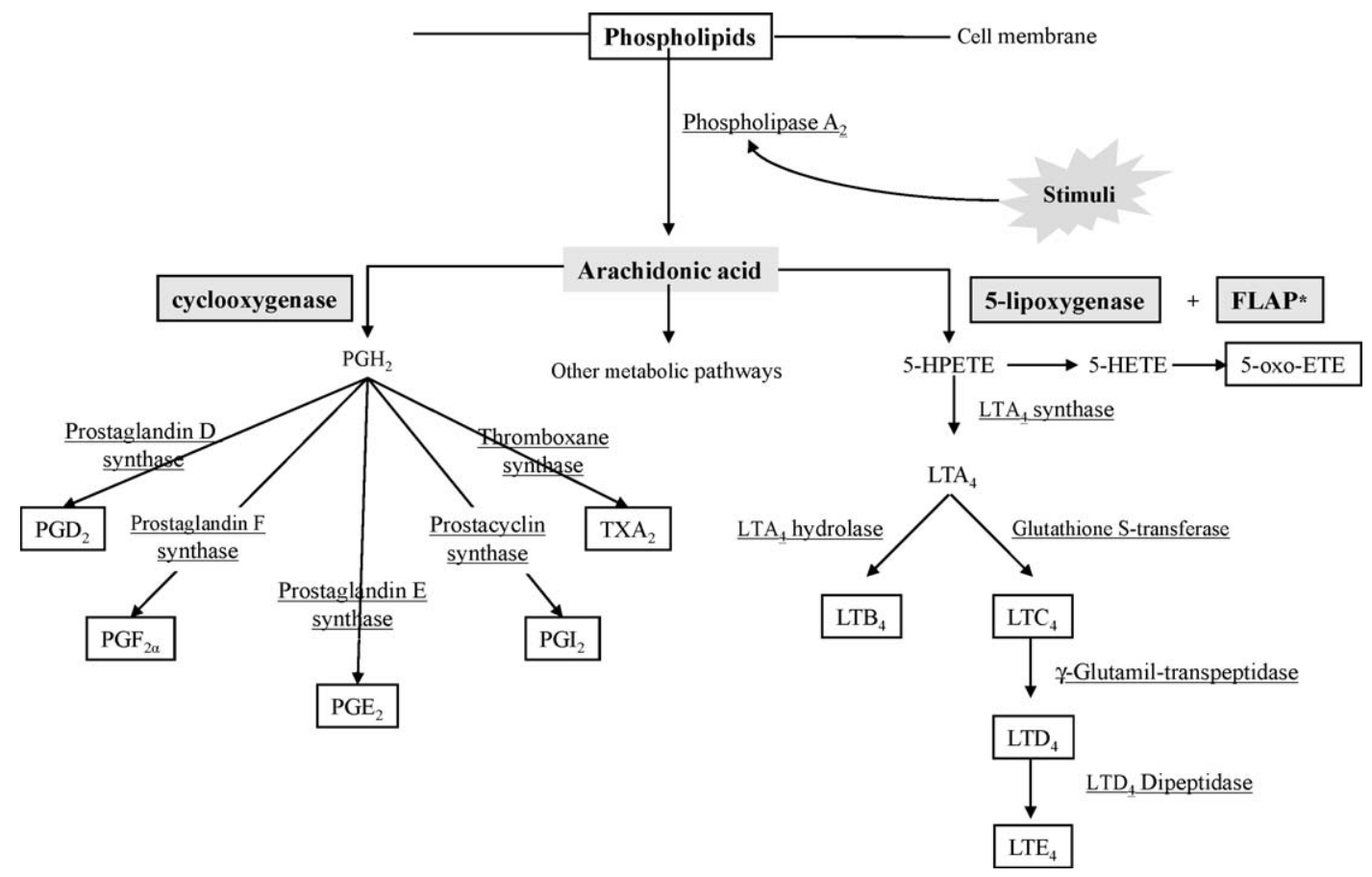

Fig. 1. Metabolism of arachidonic acid by the cyclooxygenase and 5-lipoxygenase pathways. $\left({ }^{*}\right)$ 5-Lipoxygenase-activating protein.

PGs are involved in the nociception of the inflammatory pain [4]. Thus, COX-2 isoform has been associated with acute and chronic inflammatory disorders [5] as well as in the carcinogenesis and tumor progression [3].

Lipoxygenases (LOXs) are enzymes that produce hydroxy acids and leukotrienes (LTs). From the LOXs existent in the mammalian tissues, 5-LOX, which is mainly found in cells of myeloid origin, i.e., polymorphonuclear leukocytes (PMNL), mast cells, macrophages, is the most implicated in inflammatory and allergical disorders [6]. 5-LOX metabolizes arachidonic acid to yield 5(S)-hydroxy6,8,11,14-eicosatetraenoic acid (5-HETE), which is further metabolized to the bioactive 5-oxo-6,8,11,14-eicosatetraenoic acid (5oxo-ETE) by PMNL 5-hydroxyeicosanoid dehydrogenase [7], and various LTs $\left(\mathrm{LTA}_{4}-\mathrm{LTE}_{4}\right)$ [8]. 5-oxo-ETE and $\mathrm{LTB}_{4}$, produced by PMNL, are potent chemoattractant mediators of inflammation. $\mathrm{LTB}_{4}$ stimulates neutrophil chemotaxis, enhances neutrophilendothelial interactions, and stimulates neutrophil activation, leading to degranulation and the release of mediators, enzymes, and superoxide radicals [9], while 5-oxo-ETE is much more active than $\mathrm{LTB}_{4}$ as an eosinophil chemoattractant [10]. $\mathrm{LTC}_{4}, \mathrm{LTD}_{4}$ and LTE $_{4}$, also known as Cys-leukotrienes, have shown to be essential mediators in asthma pathophysiology [11].

Although the major pathophysiological implication of LTs was considered to be the bronchial asthma, these eicosanoids contribute to the pathogenesis of other human inflammatory diseases such as rheumatoid arthritis, inflammatory bowel disease, Crohn's disease, and psoriasis (see [11-13] for reviews). Recently, the 5-LOX pathway has also been associated with atherosclerosis, osteoporosis and certain types of cancer like prostate cancer [12].

Non-steroidal anti-inflammatory drugs (NSAIDs) are the most commonly used remedy in inflammatory disorders. However, they cause several adverse effects, the most important being gastric injury up to gastric ulceration, renal failure and asthma [14]. On the other hand, the COX-2 selective drugs, generically known as COXIBs, have recently been a cause of controversy due to the enhanced cardiovascular risk they carry [13]. Thus, alternative therapeutic solutions, with similar anti-inflammatory potency but with fewer side effects, are needed, especially for the control of chronic inflammatory diseases, which implicate longer therapies.
2-Styrylchromones (2-SC) are a chemical family of oxygen heterocyclic compounds, vinylogues of flavones (2-phenylchromones), whose occurrence in nature has been reported $[15,16]$. Natural and synthetic 2-styrylchromones have been tested in different chemical and biological systems, showing activities with potential therapeutic applications [17-24]. The anti-inflammatory potential of 2-styrylchromones, concerning their interference with the arachidonic acid metabolic pathways, has not been explored so far. However, this may represent a promising field of research considering the potent inhibition of eicosanoids production by certain flavonoids containing structural similarities with 2-SC (see [25] for review). Therefore, the purpose of this work was to evaluate the inhibition of COX-1 and COX-2 activities, in a cell-free system, as well as the inhibition of $\mathrm{LTB}_{4}$ production, in human PMNL, by a group of 2-SC (Fig. 2).

\section{Material and methods}

\subsection{Reagents}

All the chemicals and reagents were of analytical grade. Hanks' balanced salt solution (HBSS), Dulbecco's phosphate buffered saline, DMSO, nordihydroguaiaretic acid (NDGA), calcium ionophore (A23187), indomethacin, iron(II) chloride, iron(III) chloride, ascorbic acid, and arachidonic acid were obtained from SigmaAldrich (Steinheim, Germany). The "Leucotriene $\mathrm{B}_{4}$ Enzyme Immunoassay (EIA) Kit" and "COX Inhibitor Screening Assay" were obtained from Cayman Chemical Co., Ann Arbor, MI, USA. Celecoxib was an offer from Pfizer. Potassium ferricyanide $\left[\mathrm{K}_{3} \mathrm{Fe}(\mathrm{CN})_{6}\right]$ and trichloroacetic acid were obtained from Merck (Darmstadt, Germany).

2-Styrylchromones $1 \mathrm{~A}-1 \mathrm{D}, 2 \mathrm{~A}-2 \mathrm{D}$ and $3 \mathrm{~A}-3 \mathrm{D}$ were synthesised by the three step Baker-Venkataraman method, starting from the $O$-protected 2 -hydroxyacetophenones and cinnamoyl chlorides [26]. The first step involves the $O$-acylation of appropriate $2^{\prime}$ hydroxyacetophenones with cinnamoyl chloride derivatives to give 2 -cinnamoyloxyacetophenones. These intermediates were converted into 5-aryl-3-hydroxy-1-(2-hydroxyaryl)-2,4-pentadien-1-ones by the base-catalysed Baker-Venkataraman rearran- 
<smiles>[R]c1cc([R])c2c(=O)cc(/C=C/c3ccc(O)c(O)c3)oc2c1</smiles>

1A: $\mathbf{R}^{1}=\mathbf{R}^{2}=\mathrm{OH}$

1B: $\mathbf{R}^{1}=\mathrm{H}, \mathbf{R}^{2}=\mathrm{OH}$

1C: $\mathbf{R}^{1}=\mathrm{OH}, \mathbf{R}^{2}=\mathrm{H}$

1D: $\mathbf{R}^{1}=\mathbf{R}^{2}=\mathbf{H}$

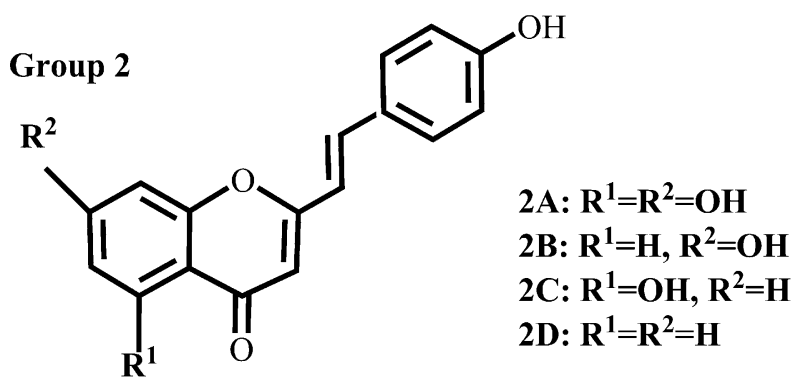

3A: $\mathbf{R}^{1}=\mathbf{R}^{2}=\mathrm{OH}$

3B: $\mathbf{R}^{1}=\mathbf{H}, \mathbf{R}^{2}=\mathrm{OH}$

3C: $\mathbf{R}^{1}=\mathbf{O H}, \mathbf{R}^{2}=\mathbf{H}$

3D: $\mathbf{R}^{1}=\mathbf{R}^{2}=\mathbf{H}$

Fig. 2. Chemical structures of the tested 2-SC.

gement [27-29]. The cyclodehydration of these $\beta$-diketones with a mixture of DMSO and a catalytic amount of iodine or $p$ toluenesulfonic acid gives polybenzyloxy-2-SC, which were debenzylated by treatment with hydrogen bromide in acetic acid at reflux, to give the expected hydroxy-2-SC 1A-1D, 2A-2D and 3A-3D.

\subsection{Equipment}

A microplate reader (Synergy HT, BIO-TEK), was used to perform the spectrophotometric readings in all the assays.

\subsection{Determination of $L_{T B}$ production by human PMNL}

Human PMNL were isolated from peripheral blood of healthy volunteers as previously described [30]. Neutrophil suspensions $\left(5 \times 10^{6}\right.$ cells $\left./ \mathrm{mL}\right)$ in HBSS were pre-incubated at $37{ }^{\circ} \mathrm{C}$ for $10 \mathrm{~min}$ with the 2-SC ( 25 and $10 \mu \mathrm{M}$ ) or with the lipoxygenase inhibitor, NDGA $(1 \mu \mathrm{M})$. The cells were subsequently incubated with A23187 $(5 \mu \mathrm{M})$ and arachidonic acid $(10 \mu \mathrm{g} / \mathrm{mL})$ for $8 \mathrm{~min}$. The reactions were stopped by the addition of cold methanol. Samples were subsequently centrifuged at $13,000 \times g$ for $1 \mathrm{~min}$, and the supernatants were stored at $-70{ }^{\circ} \mathrm{C}$ until analysis. The amount of $\mathrm{LTB}_{4}$ in the samples was measured using the above mentioned commercial EIA kit, according to the manufacturer's instructions. The results were expressed as the percent inhibition of control $\mathrm{LTB}_{4}$ production. At least four determinations were done for each experiment.

\subsection{COX-1 and COX-2 inhibition assays}

The inhibition of COX-1 (ovine) and COX-2 (human recombinant) by 2-SC was determined in a cell-free system by quantifying the levels of $\mathrm{PGF}_{2 \alpha}$, produced by catalysis of arachidonic acid, using the above mentioned specific EIA kit according to the manufacturer's instructions. The COX inhibitors indomethacin and celecoxib were used as positive controls. The results were expressed as the percent inhibition of control COX-1 or COX-2 activity. At least four determinations were done for each experiment.

\subsection{Determination of the reducing power}

The reductive potential of 2-SC was determined according to a previously described method [31]. Test compounds, in $1 \mathrm{~mL}$ of a ultrapure water/DMSO 3:1 solution, were mixed with phosphate buffer (2.5 mL, $0.2 \mathrm{M}, \mathrm{pH} 6.6$ ) and potassium ferricyanide $\left[\mathrm{K}_{3} \mathrm{Fe}(\mathrm{CN})_{6}\right](2.5 \mathrm{~mL}, 1 \% \mathrm{w} / \mathrm{v})$. The mixture was incubated at $50{ }^{\circ} \mathrm{C}$ for $20 \mathrm{~min}$. A portion $(2.5 \mathrm{~mL})$ of trichloroacetic acid $(10 \% \mathrm{w} /$ v) was added to the mixture, which was then centrifuged for $10 \mathrm{~min}$ at $3000 \mathrm{~g}$. The upper layer of the solution $(2.5 \mathrm{~mL})$ was mixed with ultrapure water $(2.5 \mathrm{~mL})$ and $\mathrm{FeCl}_{3}(0.5 \mathrm{~mL}, 0.1 \% \mathrm{w} / \mathrm{v})$, and the absorbance was measured at $700 \mathrm{~nm}$. Higher absorbance of the reaction mixture indicated greater reducing power. Ascorbic acid was used as standard compound.

\subsection{Determination of metal chelating activity}

The metal chelating activity was assessed by monitoring the changes in UV-vis spectrum of 2-SC after addition of Fe(II) [32]. Titration experiments were performed by sequential additions of $2 \mu \mathrm{L}$ of $\mathrm{FeCl}_{2}$ solution ( $300 \mu \mathrm{M}$ stock solution) to $300 \mu \mathrm{L}$ of a $10 \mu \mathrm{M}$ (final concentration) 2-SC solution. The titrations were performed in phosphate buffer $20 \mathrm{mM}$, pH 7.2.

\subsection{Cytotoxicity}

The effect of the 2-SC on the cell viability was assessed by the trypan blue exclusion method and by the release of LDH (as a measure of cell membrane integrity). The LDH activity was determined by following the rate of oxidation of NADH at $340 \mathrm{~nm}$.

\subsection{Statistical analysis}

Statistical analysis was performed by one-way analysis of variance (ANOVA) followed by Dunnett's multicomparison test using GraphPad Prism version 5.00 for Windows, GraphPad Software, San Diego California, USA, http://www.graphpad.com. When comparing with control group, values of $P$ less than 0.05 were considered significant.

Pearson correlation tests were performed using GraphPad Prism version 5.00 for Windows, GraphPad Software, San Diego California, USA, http://www.graphpad.com.

\section{Results}

\subsection{Inhibition of $L_{T B}$ production by human PMNL}

All the tested 2-SC showed to have inhibitory effects on the $\mathrm{LTB}_{4}$ production by human PMNL. 2-SC from group 1 were more effective inhibitors of $\mathrm{LTB}_{4}$ production than the correspondent compounds from the other groups. Compounds $1 \mathrm{~A}, 1 \mathrm{C}$, and $1 \mathrm{D}$, at the concentration of $25 \mu \mathrm{M}$, were able to inhibit the $\mathrm{LTB}_{4}$ production with a $\approx 90 \%$ effect, while the compound $1 \mathrm{~B}$ showed a $66.0 \pm 12.4 \%$ effect at the same concentration (Fig. 3). These 


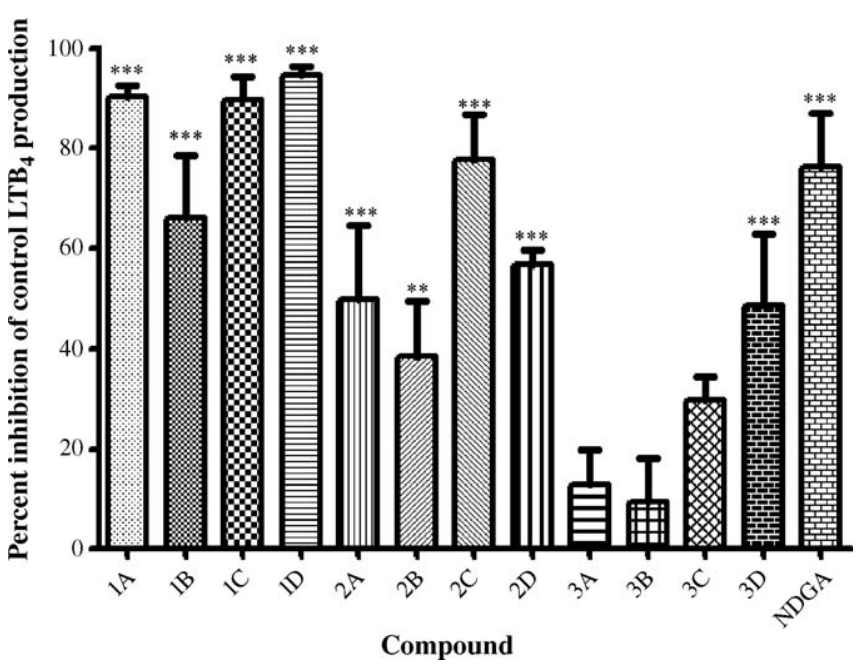

Fig. 3. Inhibition of human PMNL production of $\mathrm{LTB}_{4}$ by 2-SC $(25 \mu \mathrm{M})$ and NDGA $(1 \mu \mathrm{M})$ determined by EIA. Each value represents mean \pm SEM of at least four experiments performed in duplicate. $\left(^{* * *}\right) P<0.001,\left({ }^{* *}\right) P<0.01,\left({ }^{*}\right) P<0.05$, significantly different from control.

compounds were still very effective at the lowest tested concentration $(10 \mu \mathrm{M}), 1 \mathrm{C}$ being the strongest inhibitor $(80.9 \pm 10.1 \%$ effect, $P<0.001)$ and $1 \mathrm{~B}$ the weakest inhibitor $(38.5 \pm 11.8 \%$ effect, $P<0.01) .1$ A showed a $63.9 \pm 9.2 \%$ effect $(P<0.001)$ and 1 D showed a $62.3 \pm 7.9 \%$ effect $(P<0.001)$. The compounds from group 2 were more effective inhibitors than the correspondent compounds from group 3. $2 \mathrm{C}$ was the most effective compound from group 2, reaching a $78.0 \pm 9.0 \%$ effect at the concentration of $25 \mu \mathrm{M}$, while 3D was the most effective compound from group 3 , showing a $48.9 \pm 10.3 \%$ effect at the same concentration (Fig. 3). These compounds were still significantly effective at the concentration of $10 \mu \mathrm{M}$, where $2 \mathrm{C}$ showed an effect of $50.6 \pm 11.9 \%(P<0.001)$ and 3D showed an effect of $42.2 \pm 9.6 \%(P<0.01)$. The compounds $1 \mathrm{~B}, 2 \mathrm{~B}$, and $3 \mathrm{~B}$ were the weakest inhibitors in the respective groups. The 5-LOX inhibitor NDGA $(1 \mu \mathrm{M})$ reached a $76.1 \pm 11.0 \%$ inhibitory effect (Fig. 3 ).

\subsection{Inhibition of COX-1 and COX-2 in a cell-free system}

All 2-SC from group 1 were able to inhibit COX-1. 1A significantly inhibited the enzyme's activity at the concentrations of $100 \mu \mathrm{M}(46.0 \pm 5.6 \%)$ and $250 \mu \mathrm{M}(74.4 \pm 12.8 \%)$. 1B inhibition was only significant at $250 \mu \mathrm{M}(54.2 \pm 12.6 \%)$. Due to solubility issues, compounds $1 \mathrm{C}$ and $1 \mathrm{D}$ could only be tested at a maximum concentration of $100 \mu \mathrm{M}$, with 1D showing a significant inhibition $(24.6 \pm 6.4 \%$ ). From group 2, only $2 \mathrm{~A}$ and $2 \mathrm{~B}$ where shown to inhibit COX-1, when tested at the concentration of $250 \mu \mathrm{M}, 2 \mathrm{~A}$ being a significant inhibitor ( $66.5 \pm 11.4 \%$ ) (Fig. 4). No other 2 -SC was able to inhibit COX-1. None of the studied 2-SC inhibited COX-2 at the tested concentrations $(100 \mu \mathrm{M}$ and $250 \mu \mathrm{M})$. Indomethacin $(1 \mu \mathrm{M})$ inhibited COX-1 (26.6 $\pm 6.6 \%)$ and COX-2 $(92.6 \pm 2.1 \%)$ and the selective COX-2 inhibitor celecoxib ( $10 \mu \mathrm{M})$ could only inhibit this isoenzyme $(68.2 \pm 3.0 \%)$.

\subsection{Reducing power}

From the tested 2-SC, compounds $1 \mathrm{~A}-1 \mathrm{D}$ and $2 \mathrm{~B}$ were able to reduce, significantly, ferric ion. Compounds from group 1 were shown to be more efficient reducers than ascorbic acid (Fig. 5).

\subsection{Metal chelating activity}

The UV-vis absorption spectrum of 2-SC 1A-1D showed a common absorption peak at $380 \mathrm{~nm}$ which presented bath-

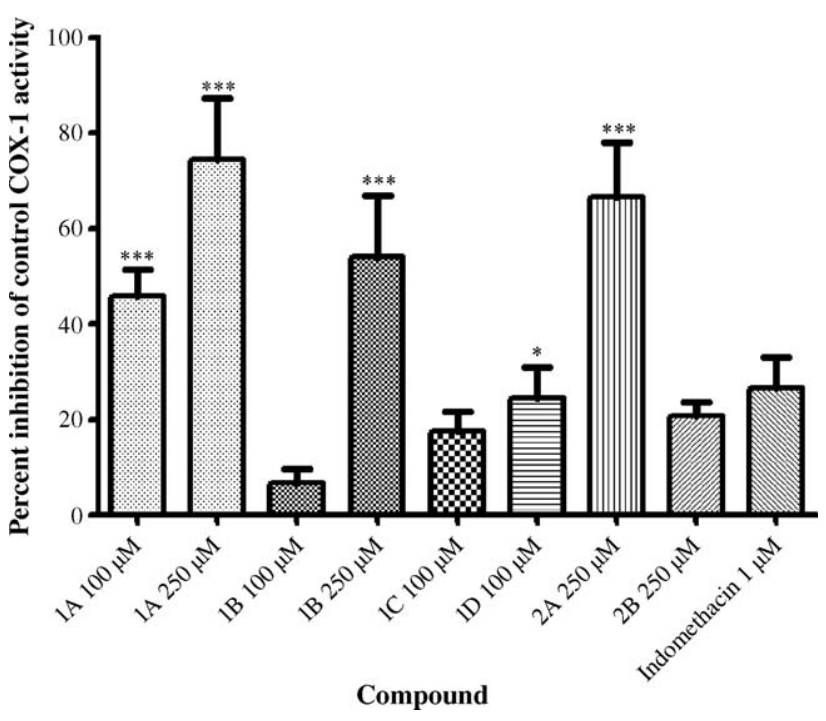

Fig. 4. Inhibition of COX-1 activity by 2-SC, determined by EIA. Each value represents mean \pm SEM of at least 4 experiments performed in duplicate. ${ }^{* * *}$ ) $P<0.001,\left(^{*}\right) P<0.05$, significantly different from control.

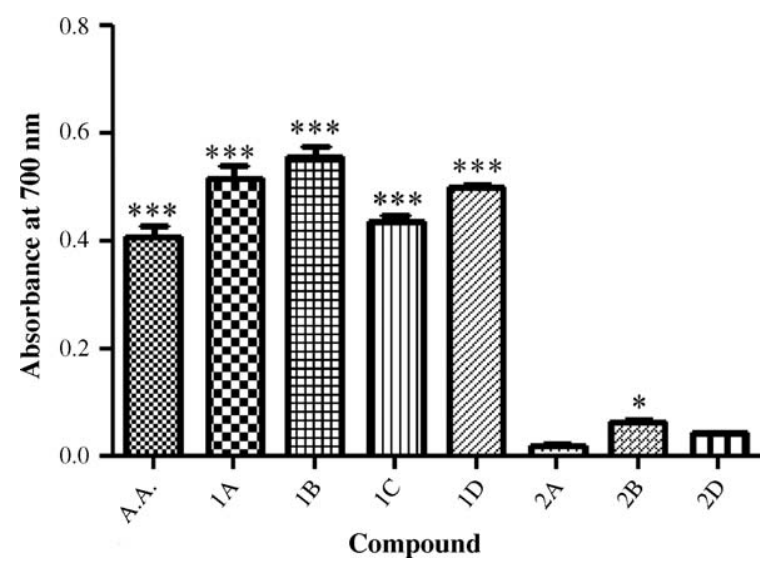

Fig. 5. Reducing activity of 2-SC and ascorbic acid (AA). All the compounds were tested at the final concentration of $25 \mu \mathrm{M}$. Each value represents mean \pm SEM of triplicate measurements. $\left.{ }^{* * *}\right) P<0.001,\left({ }^{*}\right) P<0.05$, significantly different from control.

ochromic shift upon addition of growing amounts of $\mathrm{Fe}(\mathrm{II})$, increasing gradually until the $400 \mathrm{~nm}$ (Fig. 6).

No relevant changes were observed in the UV-vis spectrum of 2-SC from groups 2 and 3 upon addition of Fe(II).

\subsection{Cytotoxicity}

None of the 2-SC caused an increased in the release of LDH compared to the control. The cell viability, assessed by the trypan blue exclusion method, was above $95 \%$ for all the compounds.

\subsection{Correlations between the inhibition of $\mathrm{LTB}_{4}$ production and scavenging activity}

Significant correlations were found between the inhibition of $\mathrm{LTB}_{4}$ production, described in Section 3.1, and the scavenging activity for singlet oxygen $\left({ }^{1} \mathrm{O}_{2}\right)$, and peroxynitrite anion $\left(\mathrm{ONOO}^{-}\right)$ (these assays were performed in a previous work [24]).

\section{Discussion}

In this work, 2-SC were tested for their anti-inflammatory potential, through their capacity to interfere with the arachidonic 

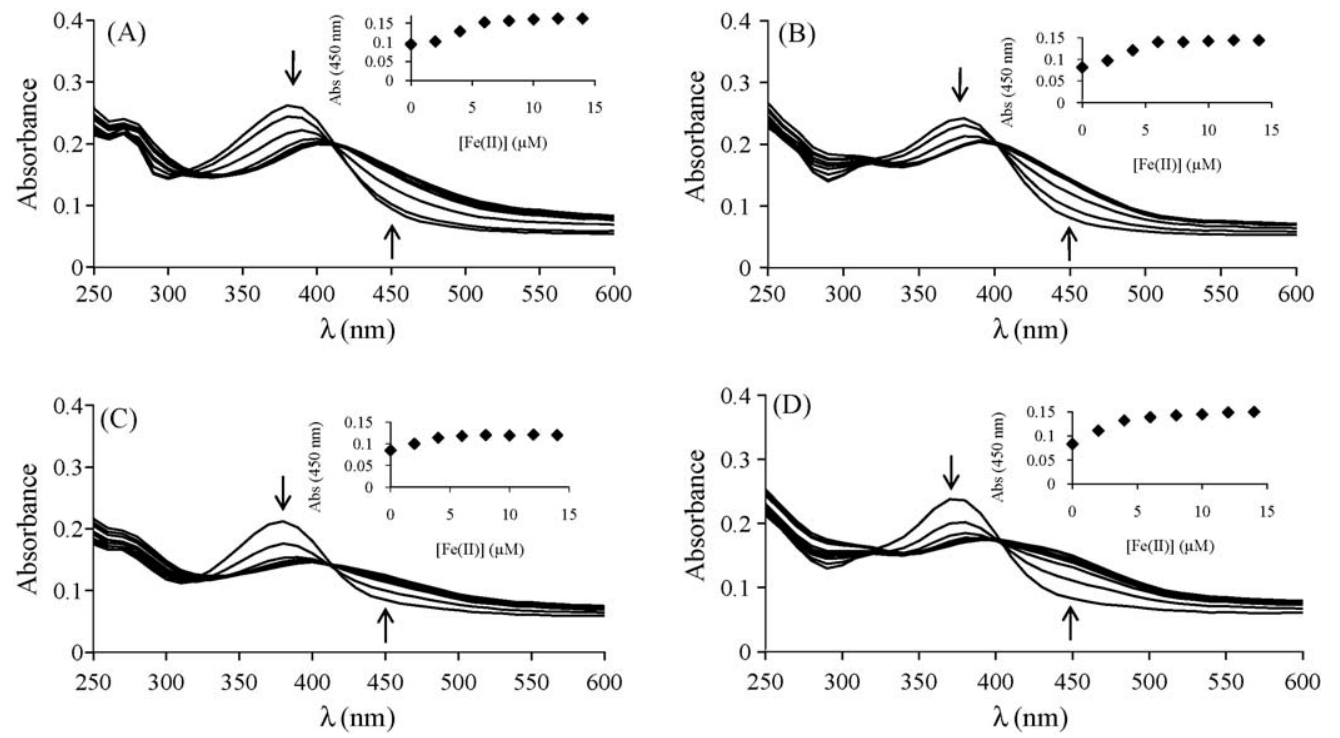

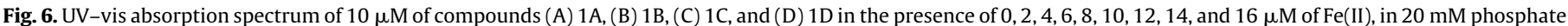
buffer, $\mathrm{pH}$ 7.2. The direction of the arrows indicates crescent amounts of Fe(II). Insets: titration curves.

acid metabolic pathways, in particular, the COX-1 and COX-2 pathways, studied in a cell-free system, and 5-LOX pathway, studied in a cellular system using human PMNL. All the studied compounds were shown to inhibit the $\mathrm{LTB}_{4}$ production by human leukocytes, especially those with a catechol substituted B-ring. This biological effect of 2-SC is shown for the first time, in the present study. As previously mentioned, 2-SC are vinylogues of flavones. Accordingly, Yoshimoto et al. [33] had previously found that the flavone structure represents a pharmacophore for 5-LOX inhibitory activity. In a recent theoretical study [34], a correlation was found between the lipoxygenase inhibitory activity of flavonoid molecules and their planar character, which probably facilitates the access, through a hydrophobic cavity, to the catalytic site of the enzyme. Considering this rationale, the planar character of 2-SC $[16,29,35]$, conferred by the styryl link between the B-ring and the C-ring, may contribute to their effectiveness as 5-LOX inhibitors.

Several mechanisms, other than a direct inhibition of 5-LOX, can explain the observed inhibition of $\mathrm{LTB}_{4}$ production by $2-\mathrm{SC}$. These include the inhibition of phospholipase $A_{2}$, and thus of the arachidonic acid release, the inhibition of LTA $_{4}$ hydrolase, or the blockade of 5-lipoxygenase activating protein. Nevertheless, it is conceivable that 2-SC, in conformity with flavonoids and other phenolic compounds, act as redox 5-LOX inhibitors. Catalytically active 5-LOX requires the conversion of $\mathrm{Fe}(\mathrm{II})$ to $\mathrm{Fe}(\mathrm{III})$, conferred by certain lipid hydroperoxides ( $\mathrm{LOOH}$ ). Most 5-LOX inhibitors act at the catalytic domain by reducing or chelating the active-site iron or by scavenging radical intermediates in the redox cycle of the iron $[6,25]$. Accordingly, the reduction of ferric ion is a possible mechanism of inhibition of $\mathrm{LTB}_{4}$ production by $2-\mathrm{SC}$, since the most effective compounds (1A-1D) also behaved as strong reducers (Fig. 3 vs. Fig. 5). Indeed, significant correlation was found between the inhibition of $\mathrm{LTB}_{4}$ production and the reducing power of the tested compounds (Table 1 ). On the other hand, the spectral changes of those compounds upon addition of $\mathrm{Fe}(\mathrm{II})$ indicate the formation of iron complexes. The similar changes in all the compounds indicate that the Fe(II)-binding site is between the ortho-hydroxyl groups in the B-ring, considered to be one "iron binding motif" in flavonoid molecules [32,36]. Furthermore, the $\mathrm{Fe}(\mathrm{II})$ titration curves reveal the formation of $1: 2 \mathrm{Fe}(\mathrm{II})$ :compound complexes (Fig. 6). Besides indicating a possible mechanism of inhibition of $\mathrm{LTB}_{4}$ production, the metal chelating capacity of the 2 -
SC from group 1, shown here for the first time, is also a very important indicator of their antioxidant activity. Finally, the capacity of some 2-SC to scavenge reactive oxygen species (ROS) and reactive nitrogen species (RNS), demonstrated in a previous study [24], is also likely to contribute to their $\mathrm{LTB}_{4}$ production inhibitory effect. Noteworthy, significant correlations were found between the inhibition of $\mathrm{LTB}_{4}$ production observed in the present study and the scavenging activity for singlet oxygen $\left({ }^{1} \mathrm{O}_{2}\right)$, and peroxynitrite anion $\left(\mathrm{ONOO}^{-}\right)$reported before (Table 1$)$.

2-SC $1 \mathrm{~A}, 1 \mathrm{~B}, 1 \mathrm{D}$ and $2 \mathrm{~A}$ where shown to significantly inhibit COX-1. This is also the first time that such biological activity of 2-SC is disclosed. On the other hand, none of the tested compounds was able to inhibit COX-2. Still, it is conceivable that this kind of effect might be seen at higher concentrations in accordance to what has been previously observed with a structural-similar compound (7,3', $4^{\prime}$-trihydroxyflavone) [37]. However, due to solubility issues, the studied 2-SC could not be tested at higher concentrations. On the other hand, several flavonoids have previously shown to inhibit COX-2 expression (see [38] for review). The flavonoid's structural features considered by others [39] as relevant for this kind of activity are shared by some of the tested 2-SC, specifically compounds $1 \mathrm{~A}$ and $2 \mathrm{~A}$. Thus, 2-SC, particularly the two referred compounds, may still be COX-2 inhibitors in vivo despite the negative results obtained in the present study.

The mechanism through which 2-SC inhibit COX-1 is likely to consist in the scavenging of the radical intermediates involved in COX enzyme catalysis, especially the phenoxy radical formed on a tyrosine residue, according to what has been previously suggested for other compounds with antioxidant moieties [40]. This mechanism is consistent with the fact that the only effective 2SC were those which have shown higher ROS and RNS scavenging effects in our previous study [24].

The capacity of some of the tested 2-SC to inhibit both COX-1 and LOX pathways plays in favour of their potential use as effective and secure anti-inflammatory drugs, when compared to the commonly used NSAIDs and COXIBs. It is well known that NSAIDs may cause several adverse effects such as gastric ulceration, renal failure and asthma. On the other hand, the safety of selective COXIBs has been recently questioned due to the apparent association of these drugs with an increased risk of cardiovascular events. The cardiovascular adverse effects are probably due to a reduction on the levels of $\mathrm{PGI}_{2}$, an important anti-thrombotic 
Table 1

Pearson correlations between the inhibition of $\mathrm{LTB}_{4}$ production and the reducing activity and between the $\mathrm{LTB}_{4}$ production and the scavenging activity against ${ }^{1} \mathrm{O}_{2}$ $\left(\mathrm{IC}_{30}\right)$ and $\mathrm{ONOO}^{-}$(with and without bicarbonate) $\left(\mathrm{IC}_{50}\right)$ [24] of the tested 2-SC.
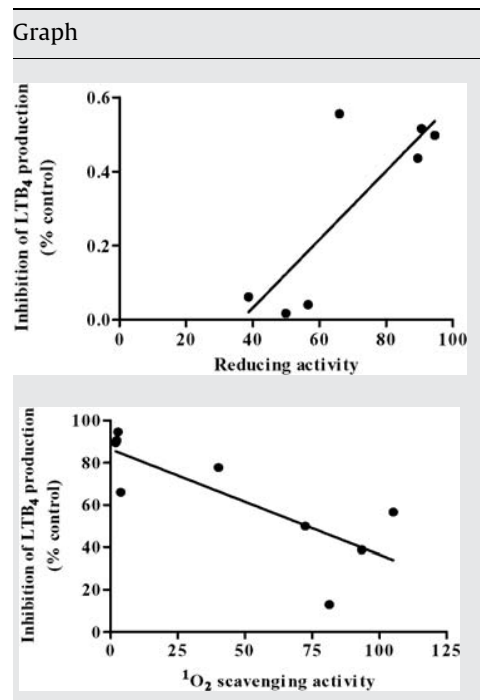

$-0.7951^{*}$

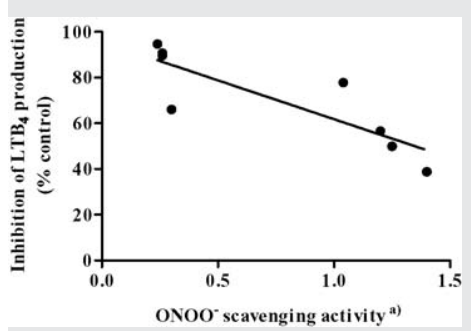

$-0.8482^{* *}$

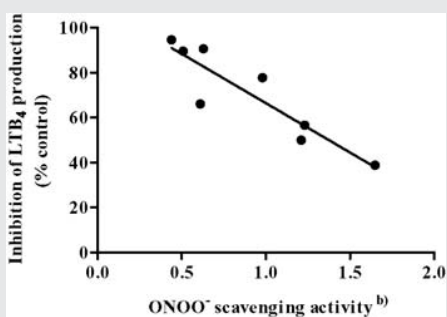

(a) Without bicarbonate; (b) with bicarbonate.

Significant at $P<0.05$.

Significant at $P<0.01$.

eicosanoid, in concomitance to an excess of thromboxane $A_{2}$, which has the opposite effect [41-43]. Considering gastric effects, COX-2 selective inhibitors can delay the repair of existing gastrointestinal damage caused by ulcers, most likely by reducing the synthesis of PGs that are thought to play an important role in the healing process [44]. In fact, the inhibition of COX pathway has to be interpreted with careful because of the diversity of COXderived mediators with different properties. Indeed, the $\mathrm{PGE}_{2}$, which has been mostly considered a pro-inflammatory mediator, has, on the other hand, given proves of involvement in antiinflammatory and pro-resolving responses [45-47]. Furthermore, the COX inhibition shunts the arachidonic acid metabolism toward the 5-LOX pathway enhancing the gastric mucosal damages due to the augmented production of $\mathrm{LTB}_{4}[44,48]$ and inducing adverse reactions in patients with asthma as a result of the cys-LTs overgeneration [44].

According to Bertolini et al. [14], dual acting anti-inflammatory drugs may represent a breakthrough in the treatment of rheumatic diseases, in view of several important arguments: (i) the same molecule (i.e., one drug alone) inhibits both COXs and 5-LOX; (ii) the inhibition of both COX isoforms ensures a high antiinflammatory efficacy and the concurrent preservation of the cardiovascular protective effects; (iii) the simultaneous inhibition of 5-LOX prevents pro-inflammatory and gastrointestinal damaging effects of leukotrienes. From our point of view, the use of dual inhibitors of the COX/5-LOX pathways seems advantageous to the treatment of other inflammatory disorders beyond rheumatic diseases. In fact, this type of compounds may exhibit antiinflammatory activity with a wider spectrum than that of classical NSAIDs by inhibiting 5-LOX product-mediated inflammatory reactions towards which NSAIDs are ineffective [44].

Importantly, it has been demonstrated that the antioxidant effect of many NSAIDs may contribute to their therapeutic effectiveness [30,49-51]. Thus, the strong antioxidant effects of 2-SC will certainly contribute to their anti-inflammatory efficacy in vivo.

In conclusion, in the present study, several of the tested 2-SC were shown, for the first time, to prevent $\mathrm{LTB}_{4}$ production by human leukocytes and to inhibit COX-1 activity. These effects, together with the well known antioxidant properties of these compounds may become a new therapeutic option in the treatment of inflammatory processes.

\section{Acknowledgements}

The authors acknowledge FCT and FEDER financial support for the project POCI/QUI/59284/2004 and the Organic Chemistry Research Unit (no. 62; Univ. Aveiro). Ana Gomes acknowledges FCT and FSE her PhD grant (SFRH/BD/23299/2005).

\section{References}

[1] Kam PCA, See AUL. Cyclo-oxygenase isoenzymes: physiological and pharmacological role. Anaesthesia 2000;55:442-9.

[2] Cipollone F, Cicolini G, Bucci M. Cyclooxygenase and prostaglandin synthases in atherosclerosis: recent insights and future perspectives. Pharmacol Ther 2008;118:161-80.

[3] Wang MT, Honn KV, Nie D. Cyclooxygenases, prostanoids, and tumor progression. Cancer Metastasis Rev 2007;26:525-34.

[4] Davies P, Bailey PJ, Goldenberg MM, Fordhutchinson AW. The rsole of Arachidonic-acid oxygenation products in pain and inflammation. Annu Rev Immunol 1984;2:335-57.

[5] Vane JR, Botting RM. Anti-inflammatory drugs and their mechanism of action. Inflamm Res 1998;47(Suppl. 2):S78-87.

[6] Jampilek J, Dolezal M, Opletalova V, Hartl J. 5-lipoxygenase, leukotrienes biosynthesis and potential antileukotrienic agents. Curr Med Chem 2006 13:117-29.

[7] Powell WS, Gravelle F, Gravel S. Metabolism of 5(S)-Hydroxy-6,8,11,14-Eicosatetraenoic acid and other $5(\mathrm{~S})$-hydroxyeicosanoids by a specific dehydrogenase in human polymorphonuclear leukocytes. J Biol Chem 1992;267: 19233-41.

[8] Samuelsson B, Dahlen SE, Lindgren JA, Rouzer CA, Serhan CN. Leukotrienes and Lipoxins - structures, biosynthesis, and biological effects. Science 1987; 237:1171-6.

[9] Busse WW. Leukotrienes and inflammation. Am J Respir Crit Care Med 1998;157:S210-3.

[10] Stamatiou P, Hamid O, Taha R, Yu WG, Issekutz TB, Rokach J, et al. 5-oxo-ETE induces pulmonary eosinophilia in an integrin-dependent manner in brown Norway rats. J Clin Invest 1998;102:2165-72.

[11] Sharma JN, Mohammed LA. The role of leukotrienes in the pathophysiology of inflammatory disorders: is there a case for revisiting leukotrienes as therapeutic targets? Inflammopharmacology 2006;14:10-6.

[12] Werz O, Steinhilber D. Therapeutic options for 5-lipoxygenase inhibitors. Pharmacol Ther 2006;112:701-18.

[13] Khanapure SP, Garvey DS, Janero DR, Letts LG. Eicosanoids in inflammation: biosynthesis, pharmacology, and therapeutic frontiers. Curr Top Med Chem 2007; 7:311-40.

[14] Bertolini A, Ottani A, Sandrini M. Selective COX-2 inhibitors and dual acting anti-inflammatory drugs: critical remarks. Curr Med Chem 2002;9:1033-43.

[15] Gerwick WH, Lopez A, Van Dyune GD, Clardy J, Ortiz W, Baez A. Hormothamnione, a novel cytotoxic styrylchromone from the marine cyanophyte Hormothamnion enteromorphoides grunow. Tetrahedron Lett 1986;27:1979-82.

[16] Gerwick WH. 6-Desmethoxyhormothamnione, a new cytotoxic styrylchromone from the marine cryptophyte Chrysophaeum taylori. J Nat Prod 1989;52:252-6.

[17] Doria G, Romeo C, Forgione A, Sberze P, Tibolla N, Corno ML, et al. Antiallergic agents. III. Substituted trans-2-ethenyl-4-oxo-4H-1-benzopyran-6-carboxylic acids. Eur J Med Chem 1979;14:347-51. 
[18] Desideri N, Conti C, Mastromarino P, Mastropaolo F. Synthesis and anti-rhinovirus activity of 2-styrylchromones. Antivir Chem Chemother 2000;11:373-81.

[19] Brion D, Le Baut G, Zammatio F, Pierre A, Atassi G, Belachm L. Preparation of 2styryl-4-chromanones as anticancer agents. European patent application EP 454:587. Chem Abstr 1991;116:106092k.

[20] Karton Y, Jiang JL, Ji XD, Melman N, Olah ME, Stiles GL, et al. Synthesis and biological activities of flavonoid derivatives as A3 adenosine receptor antagonists. J Med Chem 1996;39:2293-301.

[21] Fernandes E, Carvalho F, Silva AMS, Santos CMM, Pinto DCGA, Cavaleiro JAS, et al. 2-Styrylchromones as novel inhibitors of xanthine oxidase. A structureactivity study. J Enzyme Inhib Med Chem 2002;17:45-8.

[22] Fernandes E, Carvalho M, Carvalho F, Silva AMS, Santos CMM, Pinto DCGA et al. Hepatoprotective activity of polyhydroxylated 2-styrylchromones against tert-butylhydroperoxide induced toxicity in freshly isolated rat hepatocytes. Arch Toxicol 2003;77:500-5.

[23] Filipe P, Silva AM, Morliere P, Brito CM, Patterson LK, Hug GL, et al. Polyhydroxylated 2-styrylchromones as potent antioxidants. Biochem Pharmacol 2004;67:2207-18.

[24] Gomes A, Fernandes E, Silva AM, Santos CM, Pinto DC, Cavaleiro JA, et al. 2 Styrylchromones: novel strong scavengers of reactive oxygen and nitrogen species. Bioorg Med Chem 2007;15:6027-36.

[25] Werz O. Inhibition of 5-lipoxygenase product synthesis by natural compounds of plant origin. Planta Med 2007;73:1331-57.

[26] Santos CMM, Silva AMS, Cavaleiro JAS. Synthesis of new hydroxy-2-styrylchromones. Eur J Org Chem 2003;2003:4575-85.

[27] Baker W. Molecular rearrangement of some o-acyloxyacetophenones and the mechanism of the production of 3-acylchromones. J Chem Soc 1933;1381-9.

[28] Mahal HS, Venkataraman K. Synthetical experiments in the chromone group. Part XIV. The action of sodamide on 1-acyloxy-2-acetonaphthones. J Chem Soc 1934;1767-9.

[29] Price WA, Silva AMS, Cavaleiro JAS. 2-Styrylchromones - biological action, synthesis and Reactivity. Heterocycles 1993;36:2601-12.

[30] Costa D, Marques AP, Reis RL, Lima JLFC, Fernandes E. Inhibition of human neutrophil oxidative burst by pyrazolone derivatives. Free Radic Biol Med 2006;40:632-40.

[31] Mathew S, Abraham TE. In vitro antioxidant activity and scavenging effects of Cinnamomum verum leaf extract assayed by different methodologies. Food Chem Toxicol 2006;44:198-206.

[32] Guo M, Perez C, Wei Y, Rapoza E, Su G, Bou-Abdallah F, et al. Iron-binding properties of plant phenolics and cranberry's bio-effects. Dalton Trans 2007;4951-61.

[33] Yoshimoto T, Furukawa M, Yamamoto S, Horie T, Watanabe-Kohno S. Flavonoids: potent inhibitors of arachidonate 5-lipoxygenase. Biochem Biophys Res Commun 1983;116:612-8.

[34] Redrejo-Rodriguez M, Tejeda-Cano A, Pinto MD, Macias P. Lipoxygenase inhibition by flavonoids: semiempirical study of the structure-activity relation. J Mol Struct-Theochem 2004;674:121-4.
[35] Silva AMS, Pinto D, Tavares HR, Cavaleiro JAS, Jimeno ML, Elguero J. Novel (E)and $(Z)$-2-styrylchromones from $(E, E)$-2'-hydroxycinnamylideneacetophenones - xanthones from daylight photooxidative cyclization of (E)-2-styrylchromones. Eur J Org Chem 1998;1998:2031-8.

[36] Mira L, Fernandez MT, Santos M, Rocha R, Florencio MH, Jennings KR. Interactions of flavonoids with iron and copper ions: a mechanism for their antioxidant activity. Free Radic Res 2002;36:1199-208.

[37] Selvam C, Jachak SM, Bhutani KK. Cyclooxygenase inhibitory flavonoids from the stem bark of Semecarpus anacardium Linn. Phytother Res 2004;18:582-4.

[38] Gomes A, Fernandes E, Lima JL, Mira L, Corvo ML. Molecular mechanisms of anti-inflammatory activity mediated by flavonoids. Curr Med Chem 2008;15:1586-605.

[39] Rosenkranz HS, Thampatty BP. SAR: flavonoids and COX-2 inhibition. Oncol Res 2003;13:529-35.

[40] Dannhardt G, Laufer S. Structural approaches to explain the selectivity of COX2 inhibitors: is there a common pharmacophore. Curr Med Chem 2000; 7:1101-12

[41] Antman EM, DeMets D, Loscalzo J. Cyclooxygenase inhibition and cardiovascular risk. Circulation 2005;112:759-70.

[42] Solomon DH. Selective cyclooxygenase 2 inhibitors and cardiovascular events. Arthritis Rheum 2005;52:1968-78.

[43] Grosser T, Fries S, FitzGerald GA. Biological basis for the cardiovascular consequences of COX-2 inhibition: therapeutic challenges and opportunities. $\mathrm{J}$ Clin Invest 2006;116:4-15.

[44] Fiorucci S, Meli R, Bucci M, Cirino G. Dual inhibitors of cyclooxygenase and 5lipoxygenase. A new avenue in anti-inflammatory therapy? Biochem Pharmacol 2001;62:1433-8.

[45] Vancheri C, Mastruzzo C, Sortino MA, Crimi N. The lung as a privileged site for the beneficial actions of PGE(2). Trends Immunol 2004;25:40-6.

[46] Harizi H, Juzan M, Pitard V, Moreau JF, Gualde N. Cyclooxygenase-2-issued prostaglandin E-2 enhances the production of endogenous IL-10, which downregulates dendritic cell functions. J Immunol 2002;168:2255-63.

[47] Serhan CN. Resolution phase of inflammation: Novel endogenous anti-inflammatory and proresolving lipid mediators and pathways. Annu Rev Immunol 2007;25:101-37.

[48] Hudson N, Balsitis M, Everitt S, Hawkey CJ. Enhanced gastric-mucosal leukotriene-B(4) synthesis in patients taking nonsteroidal antiinflammatory drugs. Gut 1993;34:742-7.

[49] Fernandes E, Toste SA, Lima J, Reis S. The metabolism of sulindac enhances its scavenging activity against reactive oxygen and nitrogen species. Free Radic Biol Med 2003;35:1008-17.

[50] Fernandes E, Costa D, Toste SA, Lima JLFC, Reis S. In vitro scavenging activity for reactive oxygen and nitrogen species by nonsteroidal anti-inflammatory indole, pyrrole, and oxazole derivative drugs. Free Radic Biol Med 2004;37:1895-905.

[51] Costa D, Vieira A, Fernandes E. Dipyrone and aminopyrine are effective scavengers of reactive nitrogen species. Redox Rep 2006;11:136-42. 